Japanese Journal of Applied Physics, 34 (4A) (1995) 1837-1838

\title{
Influence of M icrocrystallite Size on Photodarkening Effects in CdS-Doped Glasses
}

Tadaki Miyoshi, Hirobumi Matsuki and Naoto Matsuo

Department of Electrical and Electronic Engineering, Yamaguchi University, Tokiwadai, U be, Yamaguchi 755, Japan

(Received November 24, 1994; accepted January 21, 1995)

Size dependence of photodarkening effects in CdS-doped glasses was investigated using luminescence and electron spin resonance (ESR). As the microcrystallite size decreases, the ESR signal associated with the photodarkening effects increases. This result indicates that the photoinduced centers responsible for the photodarkening effects are created in the interface region between $\mathrm{CdS}$ microcrystals and glass matrix.

KEYWORDS: phot odar keni ng, semi conduct or, mi crocryst al, quant um dot, I umi nescence, ESR 
Semiconductor-doped glasses show interesting optical properties. The optical properties are changed by light irradiation. These photoinduced processes are called photodarkening effects. Grabovskis et al. ${ }^{1)}$ reported that the photodarkening effects were due to traps in the host glass. In a previous paper, ${ }^{2)}$ we reported ESR spectra of CdS-doped and undoped glasses. We observed photoinduced signals, which were associated with the centers responsible for the photodarkening effects in CdS-doped glass. The signals were different from those in glass which does not contain CdS. This result indicates that the photodarkening effects are not due to centers in the host glass. Here, we report the influence of microcrystallite size on the photodarkening effects to obtain information on the photoinduced centers.

The samples investigated were CdS-doped commercial filter glasses (Toshiba Y-44, Y-45, Y-46, Y-47, Y-48) with thickness of about $2.5 \mathrm{~mm}$. These glasses were exposed to pulsed light from an $\mathrm{N}_{2}$ laser (NDC JS-1000L; wavelength $=337.1 \mathrm{~nm}$, pulse duration $=$ $5 \mathrm{~ns}$, peak intensity $=4 \mathrm{MW} / \mathrm{cm}^{2}$, repetition rate $=4 \mathrm{~Hz}$ ) at $300 \mathrm{~K}$ for $20 \mathrm{~min}$. The penetration depth of $\mathrm{N}_{2}$ laser light is less than $0.2 \mathrm{~mm}$.

The ESR spectra were measured at $77 \mathrm{~K}$, using an X-band spectrometer (JES FE-1X). The first derivative spectra were obtained by a $100 \mathrm{kHz}$ modulation. Transient characteristics of luminescence were measured using the following apparatus at $77 \mathrm{~K}$. The excitation source was an $\mathrm{N}_{2}$ laser (Laser Photonics LN120; wavelength $=337.1 \mathrm{~nm}$, pulse duration $=0.3 \mathrm{~ns}$, repetition rate $=7 \mathrm{~Hz}$ ). The laser beam was set at an angle of about $30^{\circ}$ off the normal incidence to the surface of the sample in a glass dewar and was focused on an area of about $1 \mathrm{~mm}^{2}$ by a quartz lens (focal length $\mathrm{f}=150 \mathrm{~mm}$ ). Since the peak intensity of the laser light is low $\left(50 \mathrm{~kW} / \mathrm{cm}^{2}\right)$, photodarkening effects were not observed at this intensity. Luminescence was collected normal to the sample surface, focused on the end of an optical fiber by a quartz lens ( $f=50.8 \mathrm{~mm}$ ), and then led to a $27 \mathrm{~cm}$ monochromator (Jarrel-Ash Monospec 27). Time-resolved luminescence spectra were measured using an optical multichannel analyzer with gate (Princeton Instruments D/SIDA-700). The minimum gate time is $5 \mathrm{~ns}$.

We assume that the shape of the CdS microcrystal is spherical for simplicity. Since all the glasses contain the same volume of semiconductor phase, the product of number density $\mathrm{N}$ of microcrystals and the volume of one microcrystal is constant. Thus number 
density of microcrystals is proportional to $\mathrm{r}^{-3}$. Since the surface area of microcrystals is proportional to $\mathrm{r}^{2}$, the sum of the surface area of all microcrystals in the glass is proportional to $\mathrm{r}^{-1}$.

Radius $r$ of the microcrystal is estimated according to the following procedure. The band gap $\mathrm{E}_{\mathrm{g}}$ of bulk CdS crystal is $2.37 \mathrm{eV}$ at $300 \mathrm{~K}^{3}$. Since the band gap of microcrystalline $\mathrm{CdS}$ in $\mathrm{Y}-48$ is $2.64 \mathrm{eV}$ according to the optical absorption spectrum, quantum confinement energy $E_{c}$ is $0.27 \mathrm{eV}$. Values of $E_{c}$ are proportional to $\mathrm{r}^{-2}$, so that relative value of $r$ is estimated from $E_{c}$. Values of $r$ are listed in Table I. The absolute value of $\mathrm{r}$ for $\mathrm{Y}-48\left(\mathrm{r}_{0}\right.$ in Table. $\left.\mathrm{I}\right)$ is estimated to be $2.3 \mathrm{~nm}$ according to the theoretical calculation by Brus. ${ }^{4)}$

Figure 1 shows luminescence spectra of Y-44, Y-46 and Y-48 before and after light irradiation. The luminescence spectra show two bands. One luminescence band near 2.8 $\mathrm{eV}$ is attributable to the shallow trapping state-to-band-type transition and another band near $2.2 \mathrm{eV}$ to the deep trapping state-to-band-type transition. ${ }^{5)}$ Relative intensity of the $2.2 \mathrm{eV}$ band to the $2.8 \mathrm{eV}$ band, $\mathrm{I}_{2.2} / \mathrm{I}_{2.8}$, increases with decrease in the radius. This result indicates that the $2.2 \mathrm{eV}$ band is associated with the surface states of CdS microcrystals. The value of $\mathrm{I}_{2.2} / \mathrm{I}_{2.8}$ decreases slightly after light irradiation.

The initial decay rates of the $2.8 \mathrm{eV}$ band and $2.2 \mathrm{eV}$ band were measured before and after light irradiation. The decay rates increase after light irradiation. The values of the decay rates, $\mathrm{k}_{\mathrm{b}}$ (before irradiation) and $\mathrm{k}_{\mathrm{a}}$. (after irradiation), are listed in Table $\mathrm{I}$. Difference in the decay rates, $\mathrm{k}_{\mathrm{a}}-\mathrm{k}_{\mathrm{b}}$, increases with decrease in the radius of microcrystals. This result indicates that the photodarkening effects occur easily in the glass which contains small microcrystals. The decay rate depends on radiative and nonradiative recombination channels of the excited carriers, and these channels depend on microcrystallite size, so that the decay rate is not a simple function of microcrystallite size.

Size dependence of decay rate in CdS microcrystals has been reported by Misawa et al. ${ }^{6,7)}$ They observed that the decay rate increased with radius. They considered that the size dependence was caused by the excitonic superradiance in CdS microcrystals. The size dependence is similar to that for the $2.8 \mathrm{eV}$ band in the present experiment. However, we consider that the size dependence in the present experiment is not caused 
by the superradiance, since the sample temperature $(77 \mathrm{~K})$ is higher than the threshold temperature (about $40 \mathrm{~K}$ ) of superradiance. Moreover, the decay rates in the present experiment are about $1 / 50$ of those in refs. 6 and 7. The small values of decay rates indicate that the superradiance is quenched in the present experiment.

Figure 2 shows the ESR spectra of light-irradiated CdS-doped glasses at $77 \mathrm{~K}$ : Y-44 before annealing and Y-44, Y-46 and Y-48 after annealing at $350{ }^{\circ} \mathrm{C}$ for $30 \mathrm{~min}$. We reported the correlation between the ESR signal and the photodarkening effects in a previous paper. ${ }^{2)}$ The ESR signals appear upon light irradiation and the signals except for $\mathrm{A}$ and $\mathrm{B}$ disappear after annealing at $200{ }^{\circ} \mathrm{C}$ for $15 \mathrm{~min}$. The signals $\mathrm{A}$ and $\mathrm{B}$ disappear after annealing at $400{ }^{\circ} \mathrm{C}$ for $2 \mathrm{~h}$. The photodarkening effects (decrease in luminescence intensity and increase in decay rate of luminescence) also appear upon light irradiation and disappear after annealing at $400{ }^{\circ} \mathrm{C}$ for $2 \mathrm{~h}$. This correlation between the intensity of the ESR signals and the response time in luminescence suggests that the centers responsible for the ESR signals A and B are associated with the photodarkening effects. Intensities of the signals A and B increase with decrease in the microcrystal size.

Figure 3 shows the intensity of ESR signal $\mathrm{B}$ as a function of radius $\mathrm{r}$. The ESR signal is proportional to $\mathrm{r}^{-1}$. Thus the result indicates that the signal $\mathrm{B}$ is associated with the centers at the semiconductor surface or at the glass-semiconductor interface.

We measured ESR spectra of bare fine particles of CdS. However, we did not observe the photoinduced ESR signal. Thus the signal B is associated with the centers at the glass-semiconductor interface.

In summary, luminescence and ESR of CdS-doped glasses are measured to investigate the size dependence of the photodarkening effects. The ESR signal associated with the photodarkening effects is observed. Intensity of the ESR signal is inversely proportional to the radius of microcrystals. This result indicates that the photodarkening effects are associated with the centers at the glass-semiconductor interface. 
R eferences

1) V. Ya. Grabovskis, Ya. Ya. Dzenis, A. I. Ekimov, I. A. Kudryavtsev, M. N. Tolstoi and U. T. Rogulis: Sov. Phys. Solid State 31 (1989) 149.

2) T. Miyoshi, K. Towata and N. Matsuo: Jpn. J. Appl. Phys. 33 (1994) 6299.

3) F. L. Pedrotti and D. C. Reynolds: Phys. Rev. 127 (1962) 1584.

4) L. E. Brus: J. Chem. Phys. 80 (1984) 4403.

5) K. Misawa, H. Yao, T. Hayashi and T. Kobayashi: Chem. Phys. Lett. 183 (1991) 113.

6) K. Misawa, H. Yao, T. Hayashi and T. Kobayashi: J. Chem. Phys. 94 (1991) 4131.

7) K. Misawa, H. Yao, T. Hayashi and T. Kobayashi: J. Cryst. Growth 117 (1992) 617. 


\section{Figure captions}

Fig. 1. Luminescence spectra of CdS-doped glasses at $77 \mathrm{~K}$ before and after light irradiation.

Fig. 2. ESR spectra of CdS-doped glasses at $77 \mathrm{~K}$ after light irradiation.

Fig. 3. Intensity of ESR signal B as a function of radius $r$ of CdS microcrystals. $r_{0}$ is the radius for Y-48. A straight line was drawn through the data points as a guide for the eyes. 
Table I. Decay rate of luminescence of CdS-doped glasses at $77 \mathrm{~K}$ and radius of $\mathrm{CdS}$ microcrystals. $\mathrm{k}_{\mathrm{b}}$ : decay rate before irradiation, $\mathrm{k}_{\mathrm{a}}$. decay rate after irradiation, $\mathrm{r}_{0}$ : radius for $\mathrm{Y}-48$.

$$
\text { Decay rate }\left(10^{8} \mathrm{~s}^{-1}\right)
$$

\begin{tabular}{llllll} 
Glass & \multicolumn{2}{c}{$2.8 \mathrm{eV}$ band } & \multicolumn{2}{c}{$2.2 \mathrm{eV}$ band } & Radius \\
& $\mathrm{k}_{\mathrm{b}}$ & $\mathrm{k}_{\mathrm{a}}$ & $\mathrm{k}_{\mathrm{b}}$ & $\mathrm{k}_{\mathrm{a}}$ & $\mathrm{r} / \mathrm{r}_{0}$ \\
\hline Y-44 & 0.32 & 1.33 & 0.29 & 1.18 & 0.73 \\
Y-45 & 0.20 & 1.49 & 0.09 & 0.95 & 0.77 \\
Y-46 & 0.26 & 1.43 & 0.11 & 0.48 & 0.83 \\
Y-47 & 0.47 & 1.54 & 0.08 & 0.32 & 0.90 \\
Y-48 & 0.77 & 1.82 & 0.03 & 0.15 & 1.00 \\
\hline
\end{tabular}


Fig. 1

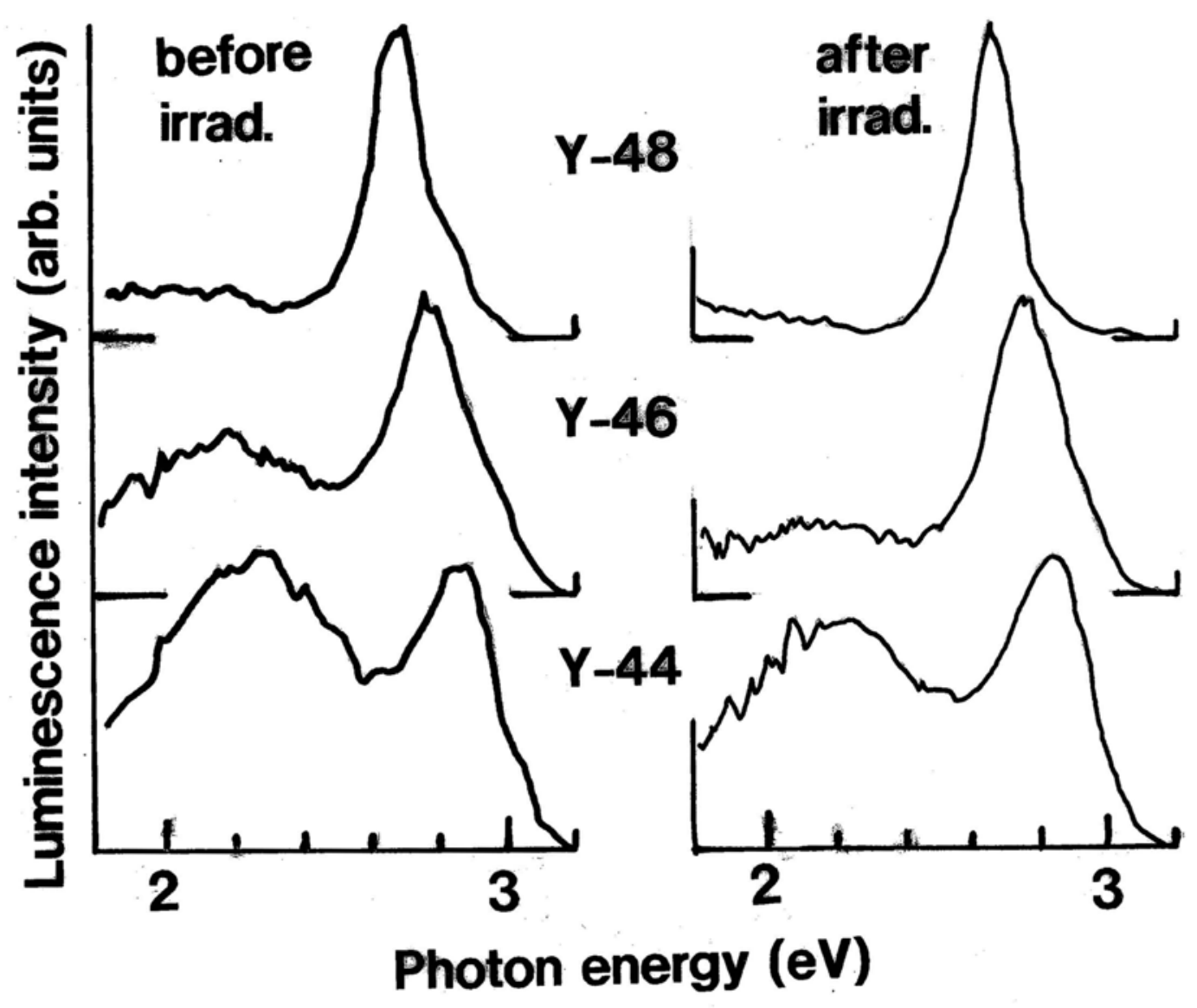


Fig. 2

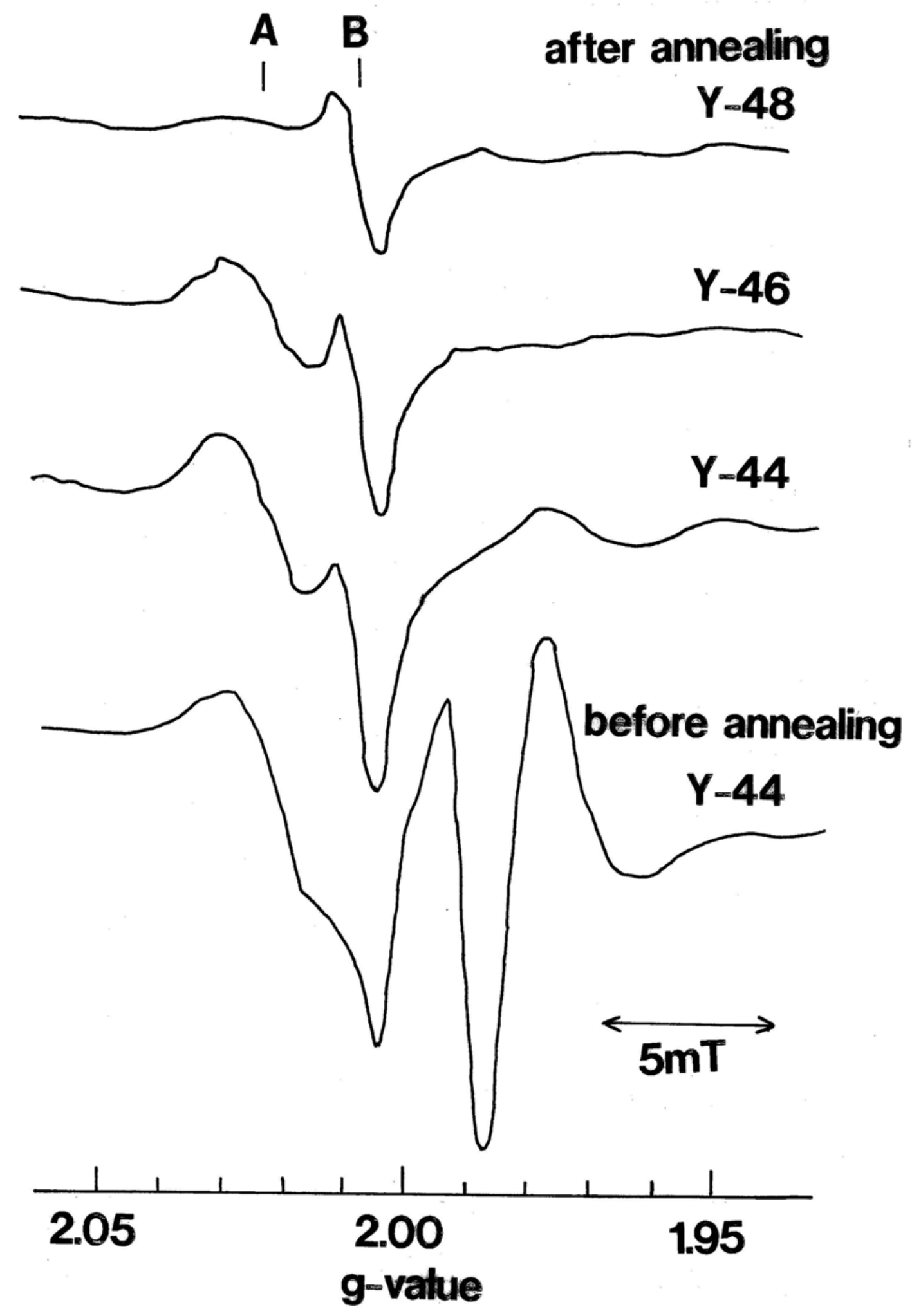


Fig. 3

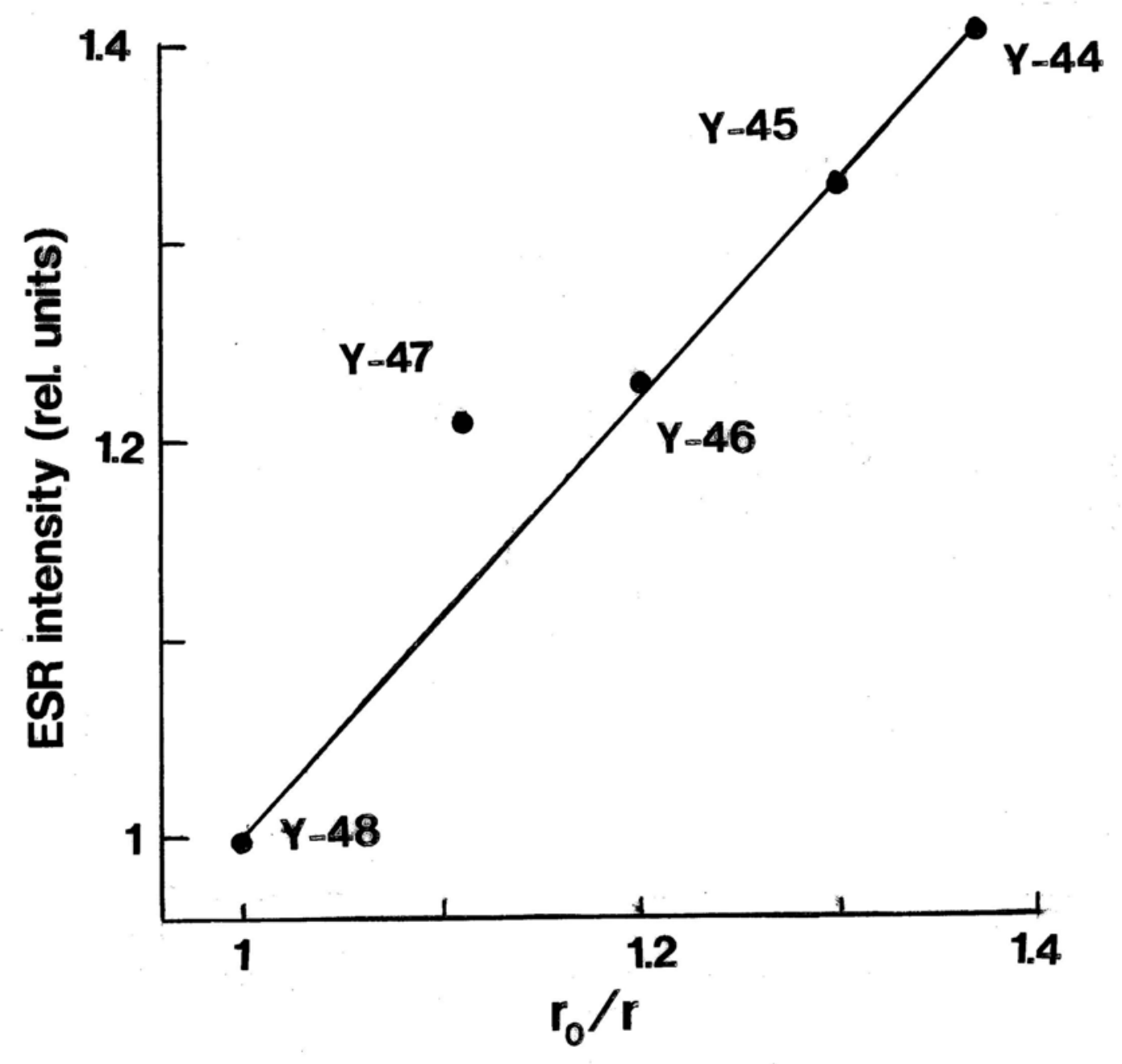

